\title{
Origins of Cortical Interneuron Subtypes
}

\author{
Qing Xu, ${ }^{1}$ Inma Cobos, ${ }^{2}$ Estanislao De La Cruz, ${ }^{1}$ John L. Rubenstein, ${ }^{2}$ and Stewart A. Anderson ${ }^{1}$ \\ ${ }^{1}$ Department of Psychiatry, Weill Medical College of Cornell University, New York, New York 10021, and ${ }^{2}$ Department of Psychiatry, University of \\ California, San Francisco, San Francisco, California 94143
}

Cerebral cortical functions are conducted by two general classes of neurons: glutamatergic projection neurons and GABAergic interneurons. Distinct interneuron subtypes serve distinct roles in modulating cortical activity and can be differentially affected in cortical diseases, but little is known about the mechanisms for generating their diversity. Recent evidence suggests that many cortical interneurons originate within the subcortical telencephalon and then migrate tangentially into the overlying cortex. To test the hypothesis that distinct interneuron subtypes are derived from distinct telencephalic subdivisions, we have used an in vitro assay to assess the developmental potential of subregions of the telencephalic proliferative zone $(\mathrm{PZ})$ to give rise to neurochemically defined interneuron subgroups. $\mathrm{PZ}$ cells from $\mathrm{GFP}^{+}$donor mouse embryos were transplanted onto neonatal cortical feeder cells and assessed for their ability to generate specific interneuron subtypes. Our results suggest that the parvalbumin- and the somatostatin-expressing interneuron subgroups originate primarily within the medial ganglionic eminence (MGE) of the subcortical telencephalon, whereas the calretinin-expressing interneurons appear to derive mainly from the caudal ganglionic eminence (CGE). These results are supported by findings from primary cultures of cortex from Nkx2.1 mutants, in which normal MGE fails to form but in which the CGE is less affected. In these cultures, parvalbumin- and somatostatin-expressing cells are absent, although calretinin-expressing interneurons are present. Interestingly, calretinin-expressing bipolar interneurons were nearly absent from cortical cultures of $D l x 1 / 2$ mutants. By establishing spatial differences in the origins of interneuron subtypes, these studies lay the groundwork for elucidating the molecular bases for their distinct differentiation pathways.

Key words: interneuron; cortex; $N k x 2.1$; parvalbumin; somatostatin; calretinin

\section{Introduction}

The cerebral cortex (including the neocortex, hippocampus, and paleocortex) functions in memory and higher-order cognitive processing. These functions are served by essentially two classes of neurons: excitatory projection neurons and inhibitory interneurons. The interneurons, which comprise $20-30 \%$ of cortical neurons, serve a vital role in modulating cortical output (Cherubini and Conti, 2001; Krimer and Goldman-Rakic, 2001). In addition, they appear to regulate neuronal proliferation and migration later in corticogenesis (Owens and Kriegstein, 2002), as well as the postnatal development of cortical circuitry (Huang et al., 1999; Fagiolini and Hensch, 2000; Zheng and Knudsen, 2001). The specific functions of cortical interneurons are conducted by a remarkable diversity of distinct subtypes that differ by axonal and dendritic morphology (Ramon y Cajal, 1911; Lund and Lewis, 1993) and chemical markers (DeFelipe, 1993; Gonchar and Burkhalter, 1997), as well as connectivity and physiology (Cauli et al., 1997; Kawaguchi and Kubota, 1997).

Unlike cortical projection neurons, which derive from the

Received 0ct. 20, 2003; revised Jan. 26, 2004; accepted Jan. 27, 2004.

This work was supported by grants from the National Alliance for Research on Schizophrenia and Depression (I.C. S.A.A.), the National Institute of Mental Health (J.R., S.A.A.), and the EJLB Foundation (S.A.A.). We thank Carrie Horn for technical assistance.

Correspondence should be addressed to Dr. Stewart Anderson, Weill Medical College of Cornell University, 1300 York Avenue, Box 244, New York, NY 10021. E-mail: saa2007@med.cornell.edu.

DOI:10.1523/JNEUROSCI.5667-03.2004

Copyright $\odot 2004$ Society for Neuroscience $\quad$ 0270-6474/04/242612-11\$15.00/0 dorsal telencephalon (Chan et al., 2001; Gorski et al., 2002), many cortical interneurons derive from the ventral (subcortical) telencephalon in the anlage of the basal ganglia (for review, see Parnavelas, 2000; Corbin et al., 2001; Marin and Rubenstein, 2001). Studies of interneuron migrations in explants (Lavdas et al., 1999; Wichterle et al., 1999), as well as fate-mapping experiments in vitro (Anderson et al., 2001) and in vivo (Wichterle et al., 2001; Anderson et al., 2002), suggest that the medial ganglionic eminence (MGE) is the primary source of cortical interneurons in rodents; however, several other sources of cortical interneurons have been implicated. First, both the lateral ganglionic eminence (LGE) and the caudal ganglionic eminence (CGE) give rise to cortical interneurons (Anderson et al., 2001; Jimenez et al., 2002; Nery et al., 2002). In addition, on the basis of immunohistochemical stainings, the rostral, "retrobulbar" neuroepithelium of the lateral ventricle also appears to give rise to interneurons that migrate into the overlying cortex (Meyer et al., 1998; Ang et al., 2003). Finally, it has recently been reported that in humans more than half of the cortical interneurons derive from mitoses within the cortical subventricular zone (SVZ) (Letinic et al., 2002). In rodents cortical progenitors also give rise to GABA-expressing cells in vitro (Götz et al., 1995; He et al., 2001; Bellion et al., 2003; Nery et al., 2003), although it is unclear whether these derive from migratory cells of subcortical origin and whether they differentiate into interneurons within the postnatal cortex (Xu et al., 2003).

The existence of distinct sources of cortical interneurons begs the question: do distinct interneuron subtypes derive from dis- 
tinct sources? Although this question has not been systematically addressed previously, fate-mapping experiments in vivo suggest that parvalbumin $(\mathrm{Pv})$-and somatostatin-expressing interneurons derive from the MGE but that calretinin-expressing interneurons do so rarely or not at all (Wichterle et al., 2001; Anderson et al., 2002; Valcanis and Tan, 2003). In light of findings that parvalbumin, somatostatin, and calretinin label essentially distinct interneuron subgroups in rats (Kubota et al., 1994; Gonchar and Burkhalter, 1997) and mice (Q. Xu and S. A. Anderson, unpublished results) and have distinct physiological characteristics (Kawaguchi and Kubota, 1996; Cauli et al., 1997), these studies suggest that interneuron subgroups may have distinct spatial or temporal origins. Indeed, evidence suggests that somatostatinexpressing cells within superficial cortical layers leave the cell cycle before those that express vasoactive intestinal protein (Cavanagh and Parnavelas, 1988, 1989), a peptide that is coexpressed to a large extent with calretinin (Rogers, 1992).

Despite the relevance to cortical function (Rao et al., 2000) and dysfunction (DeFelipe, 1999; Lewis, 2000), little is known about the specification of interneuron subtypes. One reason lies in the fact that interneuron maturation is completed postnatally (Gao et al., 2000), such that in rodents adult patterns of neurochemically defined interneuron subgroups are not achieved until at least the third postnatal week (Alcantara et al., 1996). Thus, systematic analysis of the effectors of interneuron subtype specification requires the capability of studying the postnatal effects of alterations made weeks previously, without producing other alterations in cortical development that could secondarily impact interneuron maturation. In this study, a cell transplantation system is used to examine the differential potential of telencephalic regions to produce distinct interneuron subtypes after plating over feeder layers from neonatal cortex. Findings from these experiments are complementary to results from primary cultures of Nkx2.1 mutants and strongly suggest that somatostatin- and parvalbumin-expressing subgroups derive primarily from the MGE. In contrast, calretinin-expressing interneurons appear to originate mostly within the CGE. In addition to the important implications for the generation of cortical interneuron diversity, this study presents a new approach for the systematic analysis of factors involved in cortical interneuron development.

\section{Materials and Methods}

Animals. Green fluorescent protein (GFP)-expressing transgenic mice (a kind gift from Andras Nagy, University of Toronto, Ontario, Canada) (Hadjantonakis et al., 1998) were maintained on a CD1 background. Matings of hemizygous $\mathrm{GFP}(+)$ males with wild-type $\mathrm{CD} 1$ females were used to generate both $\mathrm{GFP}(+)$ embryos for donor tissue and $\mathrm{GFP}(-)$ pups for making cortical feeder cultures. To generate $\mathrm{GFP}(+), N k \times 2.1$ null mice and Nkx2.1+/- mice (a gift from S. Kimura, National Cancer Institute, Bethesda, MD) were bred into the CD1-GFP line over 10 generations. This outbreeding of the $N k \times 2.1$ line did not appear to alter either the lung agenesis or the ventral telencephalic phenotypes described previously in these mice (Kimura et al., 1996; Sussel et al., 1999). GFP(-), Nkx2.1+/- breeders from this line were crossed to produce the embryonic day (E) 18.5 mice used in Figure 1.

Mutant mice lacking functional copies of both $D l x 1$ and $D l x 2(D l x 1 / 2)$ were maintained as heterozygotes on a C57B6/J background. Genotyping was determined by morphological assessment (cleft palate in $D l \times 1 / 2$ nulls and absence of lungs and the MGE-LGE sulcus in Nkx2.1 nulls) and confirmed by PCR as described previously (Anderson et al., 1997a; Sussel et al., 1999).

For staging of embryos, midday of the day of vaginal plug formation was considered as E0.5. Mouse colonies were maintained in accordance with the guidelines set by the authors' institutions and the National Institutes of Health.
Preparation of primary cortical cultures and cortical feeder cells. Primary cortical cultures were prepared as described previously (Anderson et al., 1997a). Briefly, day of birth (P0) or P1 neonates (E18.5 in the case of the primary cultures from $N k \times 2.1$ or Dlx1/2 mutants) were decapitated, and their brains were removed into ice-cold HBSS (Cellgro). The neocortex was then dissected into Neurobasal/B27 medium [Nb/B27 (Invitrogen, Gaithersburg, $\mathrm{MD}$ ); macerated using fine forceps, and trypsinized $\left(0.05 \%\right.$ trypsin, $\left.\left.37^{\circ} \mathrm{C}, 15 \mathrm{~min}\right)\right]$ in the presence of $1 \mathrm{U} / \mathrm{ml}$ DNase (Promega, Madison, WI). Cells were then triturated using a fire-polished Pasteur pipette and resuspended in DMEM (Invitrogen) with 10\% FBS; $1 \times 10^{5}$ cells in $100 \mu l$ were added to each well of 16-well chamber slides (36 $\mathrm{mm}^{2}$; Lab-Tek) that were previously coated with polylysine $(10 \mu \mathrm{g} /$ $\mathrm{ml})$ and then laminin $(5 \mu \mathrm{g} / \mathrm{ml})$. Cultures were maintained at $37^{\circ} \mathrm{C}$ in $5 \%$ $\mathrm{CO}_{2}$ and ambient oxygen.

Preparation and transplantation of donor cells. Embryos were harvested from killed dams and placed into ice-cold HBSS. After identification of GFP + embryos, brains were embedded in $4 \%$ low-melt agarose (EM Science) in $\mathrm{HBSS}$ at $42^{\circ} \mathrm{C}$ and sectioned into $300 \mu \mathrm{m}$ slices in the coronal plane using a Vibratome (Leica VT1000S). Sections were then placed into $\mathrm{Nb} / \mathrm{B} 27$, and the periventricular proliferative zones of the appropriate tissues were dissected free. These regions are distinguishable from adjacent mantle regions because the increased cell density of the proliferative tissue is visible under dark-field optics. Tissues were then macerated with fine forceps, trypsinized as above without the addition of DNase, gently triturated, and then resuspended in $\mathrm{Nb} / \mathrm{B} 27$ medium.

Five hundred donor cells per well were then added to cortical feeder cultures prepared $1 \mathrm{~d}$ previously. For donors aged E12.5 and E14.5, 100 $(20 \%)$ cells survived and differentiated into neurons when assessed after $14 \mathrm{~d}$ in vitro (DIV). Increasing numbers of glia were found from later donors, although no wells were counted that had fewer than 20 neurons in the well. The donor cells were added to the feeder cultures in a $50 \mu \mathrm{l}$ volume of $\mathrm{Nb} / \mathrm{B} 27$ medium that was exchanged for an equal volume of the feeder medium (DMEM plus 10\% FBS). The next day (1 DIV), $50 \mu \mathrm{l}$ of the medium was exchanged with $\mathrm{Nb} / \mathrm{B} 27$ medium containing 10 $\mathrm{ng} / \mathrm{ml}$ of basic FGF (Promega), and the same exchange was conducted every other day for the remaining time of culture. This approach promotes the initial proliferation of astroglia that grossly mimics what occurs in the early postnatal cortex in vivo.

For most of the experiments, the cells were cultured for 10-14 DIV. For detection of the parvalbumin-expressing cells, cultures ran for 28 DIV.

Immunohistological analysis of primary cultures. Cultures were fixed in $4 \%$ paraformaldehyde in PBS, and donor cells were examined by epifluorescence microscopy (Nikon E800) by virtue of their fluorescence, or by immunolabeling with anti-GFP antibodies (from rabbit or chick hosts; Molecular Probes, Eugene, OR) and fluorescent secondary antibodies (Alexa line; Molecular Probes). This latter method results in a strong epifluorescent signal that permits an apparently full visualization of donor cells, including dendritic and axonal processes. In addition, donor cells were characterized by colabeling. The primary antibodies that were used included glutamate (rabbit host; Sigma, St. Louis, MO; 1:5000), GABA (rabbit; Sigma; 1:5000), reelin, (G10, mouse; a kind gift from Andre Goffinet, University of Louvain, Brussels, Belgium; 1:1000), neuropeptide Y (NPY) (rabbit; Immunostar; 1:2000), somatostatin (rat; Chemicon, Temecula, CA; 1:400), parvalbumin (mouse; Chemicon; 1:5000), calretinin (rabbit; Chemicon; 1:2000), and calretinin (mouse; Swant; 1:5000). Triple labeling for GABA was accomplished with Cy5conjugated anti-rabbit secondary antibodies (Molecular Probes).

Proliferation by transplanted progenitors was measured by adding bromodeoxyuridine (BrdU; $1 \mathrm{ng} / \mathrm{ml} ; 3 \mathrm{nM}$ ) to the culture medium for 24 hr. BrdU incorporation was detected by pretreatment with nuclease (Amersham Biosciences, Arlington Heights, IL) at $37^{\circ} \mathrm{C}$ for $30 \mathrm{~min}$ followed by double-labeling [rabbit anti-GFP, 1:2000 (Molecular Probes), and mouse anti-BrdU (Chemicon), 1:400; visualized with 488 or 594 Alexa-Fluor secondary antibodies] or triple-labeling immunofluorescence [chick anti-GFP, 1:2000 (Molecular Probes); rabbit anti-calretinin and mouse anti-BrdU]. For triple labeling the mouse anti-BrdU was detected using Cy5 anti-mouse secondary antibodies (Molecular Probes) imaged with a cooled digital camera (Coolsnap HQ, Roper) and Meta- 
morph software. Specificity of secondary antibodies was confirmed by comparing labeling in the presence or absence of primary antibodies.

Data collection and statistical analysis. For the primary cultures of mutant and $+/$ ? cortices, for each antibody examined data were collected from duplicate wells of at least $3-/-$ and $+/$ ? littermate pairs. For the transplantation studies, data were collected from duplicate wells of at least three donor samples. Donor cells that had differentiated into neurons (the vast majority of donors from E12.5 and E14.5, and a minority of donors from E16.5 and later) were identified by the presence of at least two thin processes emanating from the soma, although in most cases an extensive dendritic and axonal arborization was visible. The characterization of $100 \%$ of these cells as neurons was established through pilot studies with the neuronal markers $\beta$ IIItubulin and MAP2. Statistical analysis ( $t$ test and ANOVA) was conducted using Statview software.

Neuronal birth dating with BrdU. To label a large cohort of neurons born on a particular day of gestation so that adequate numbers of the relatively rare calretinin + interneurons could be labeled per section, injections of $\mathrm{BrdU}(50 \mathrm{mg} / \mathrm{kg}$, i.p.) were made every $2 \mathrm{hr}$ times five. Twenty-five days after birth, animals (three animals for each age of injection: E12.5, E14.5, E16.5, E18.5, P1) were deeply anesthetized and perfused with $4 \%$ paraformaldehyde in PBS, and the brains were removed and postfixed for $4 \mathrm{hr}$. After cryoprotection in 30\% sucrose and embedding in OCT (Tissue Tek), $10 \mu \mathrm{m}$ sections in the coronal plane were cut onto glass slides (Superfrost Plus) and stored at $-80^{\circ} \mathrm{C}$. Sections were processed for BrdU labeling by incubation in 50\% formamide, $2 \times$ SSC at $55^{\circ} \mathrm{C}$ for $10 \mathrm{~min}$, and then $2 \mathrm{~N} \mathrm{HCl}$ in PBS at $37^{\circ} \mathrm{C}$ for $20 \mathrm{~min}$ followed by $0.1 \mathrm{~m}$ boric acid for $2 \mathrm{~min}$. Sections were then rinsed, blocked in 10\% FBS, and incubated in mouse anti-calretinin (Swant; 1:2000) and rat anti-BrdU (Serotec; $1: 500$ ) overnight at $4^{\circ} \mathrm{C}$. Primary antibodies were visualized using Alexa-594 anti-rat and Alexa- 488 anti-mouse secondary antibodies (Molecular Probes). Cells were counted using a $60 \times$ oil emersion lens (numerical aperture 1.4) on a Nikon E800 microscope fitted with epifluorescence. False counts of double-labeled cells were unlikely because in most cases the BrdU-labeled nucleus could be seen to fit into an area of lower calretinin signal in the cell body (see Fig. 7). The reliability of the counting method was confirmed, however, by comparing stacks of images taken using a Z-drive, $100 \times$ objective and two-dimensional deconvolution software (Metamorph, Universal Imaging).

To quantify calretinin and BrdU double labeling, both hemispheres of 12 nonserial sections of each brain were examined. Sections were counted rostral to the genu of the corpus callosum and caudal to the hippocampal commissure, and counts were made within layers II-VI of primary somatosensory cortex on the basis of comparison with Nisslstained sections with the aid of the mouse atlas of Franklin and Paxinos (1997).

\section{Results}

Loss of $N k x 2.1$ has differential effects on the development of cortical interneuron subtypes

The cerebral cortex of $N k \times 2.1-/-$ mutants, in which a normal MGE fails to form, contains roughly half the normal number of cortical GABA-expressing cells at E18.5 (Sussel et al., 1999). At E18.5, however, interneurons that express somatostatin are almost completely absent (Anderson et al., 2001). Neurons expressing NPY, which later in development are expressed primarily in subsets of somatostatinexpressing interneurons (Kubota et al., 1994; Gonchar and Burkhalter, 1997), are also reduced $>95 \%$ in these mutants. Unfortunately Nkx2.1-/- mice die at birth because of the absence of lung development (Kimura et al., 1996). To examine the postnatal develop- ment of interneuron subtypes in these mutants, primary cultures were made from dissociated cortices of $N k \times 2.1-/-$ embryos and their $+/+$ littermates at E18.5. Subpopulations of neurons from $+/+$ embryos expressed somatostatin and NPY after 14 DIV, and parvalbumin-expressing cells were detectable after 28 DIV (Fig. 1). Consistent with these markers labeling subpopulations of interneurons, most of the somatostatin (98\%; 338 of 345)- and parvalbumin (88.5\%; 499 of 564)-expressing cells colabeled with GABA, and colabeling of somatostatin with parvalbumin after 28 DIV was rare (3.3\%; 6 of 220). In stark contrast to results from wild-type cortices, essentially no cells in cortical cultures from $N k \times 2.1-/-$ embryos expressed detectable levels of somatostatin, NPY, or parvalbumin (Fig. 1).

Calretinin, a calcium-binding protein that in cortical tissue sections is expressed primarily in small, bipolar, or bitufted interneurons (Schierle et al., 1997), was also expressed in similarly shaped neurons in cultures from wild types. After 14 DIV, $84.6 \%$ of calretinin + cells (523 of 618) colabeled for GABA. Unlike the parvalbumin- or somatostatin-expressing interneuron subgroups, calretinin-expressing bipolar neurons (a cell type that does not strongly express the Cajal-Retzius cell marker reelin; see Figs. 8 and 9) were present in similar numbers in both $+/+$ and $-I-$ cultures (Fig. 1). These results suggest that the parvalbumin- or somatostatin-expressing interneuron subgroups require a normal MGE for their development, whereas calretinin-expressing interneurons do not.

\section{Differential potential of telencephalic progenitor domains to generate glutamatergic or GABAergic neurons}

Although the analysis of Nkx2.1 mutants is consistent with differential origins of somatostatin- or parvalbumin-expressing interneurons versus those that express calretinin, it is conceivable that the specification of the former subgroups requires normal development of the MGE but that they do not derive from the MGE itself. Indeed Sonic Hedgehog (Shh), a morphogen that specifies neuronal subtypes in the ventral spinal cord, is greatly reduced in the ventral telencephalon of $N k \times 2.1$ mutants (Sussel et al., 1999; Nery et al., 2001).

To systematically examine the potential of telencephalic progenitor zones to generate cortical interneurons, we developed a transplantation system designed to study progenitor fate poten- 
A
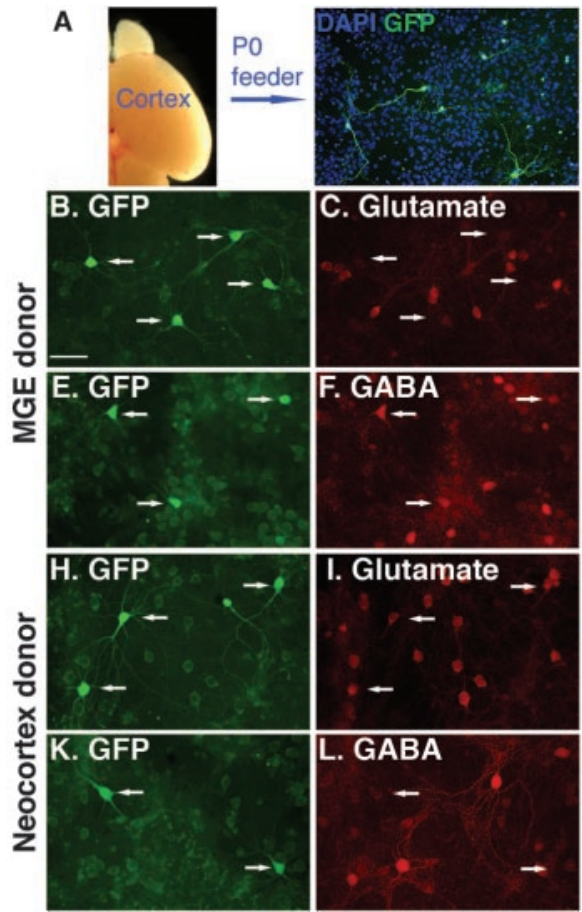
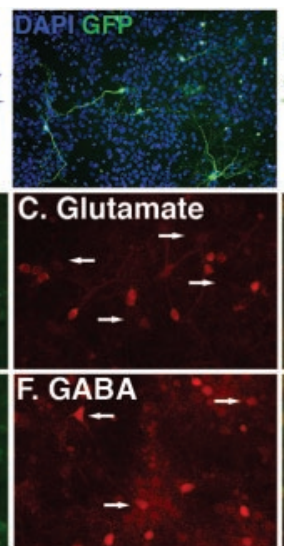

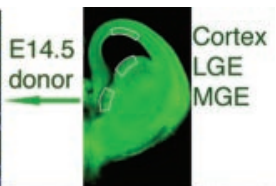

D. merge
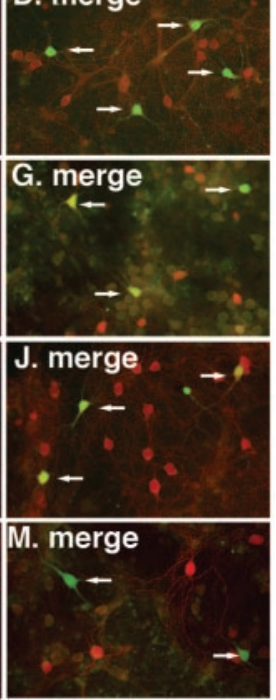

Figure 2. Differential expression of GABA or glutamate in donor cells from the proliferative zone of the MGE or cortex. In this experiment the MGE or neocortex of E14.5 donors was plated onto neonatal cortex feeders and cultured for 2 weeks. Each row of three panels shows identical fields: the left row $(B, E, H, K)$ shows GFP expression by the donor cells, the middle row shows expression of glutamate $(C, I)$ or $G A B A(F, L)$, and the right row shows the merged images. Few donors from the MGE $(B-D)$ express high levels of glutamate, whereas many more express $G A B A(E-G)$. In contrast, most cortical donors $(H-J)$ strongly express glutamate, whereas few express high levels of GABA $(K-M)$. Scale bar, $50 \mu \mathrm{m}$.

tial in the context of a cortical environment in vitro. First, donor cells are prepared by dissociating telencephalic progenitor zones from mice that express GFP under control of the chicken $\beta$-actin promoter (Lobe et al., 1999). These cells are then plated at low density onto high-density feeder layers made from dissociated cortices $1 \mathrm{~d}$ previously. The fates of donor cells are then assessed by epifluorescence immunolabeling.

Previous studies in rodents have indicated that most projection neurons derive from the dorsal, pallial portion of the telencephalon, whereas most cortical interneurons derive from the telencephalic pallidum (Anderson et al., 1997, 2001; Gorski et al., 2002). Primary cultures, however, taken from the cortex at a time when relatively few migratory interneurons should have reached the cortex, none the less gave rise to a large percentage (30\%) of GABA expressing neurons (Götz et al., 1995). To determine whether the predicted glutamatergic or GABAergic fate is maintained in this transplantation system, progenitor domains were compared for their ability to generate cells that express GABA or glutamate. As expected, most of the surviving cells from MGE transplants onto cortical feeder cells express GABA, whereas most of the cortical transplants express glutamate (Figs. 2, 3). This difference was most striking from donors dissected at E12.5, when few subcortically derived interneurons would have reached the neocortex. The results from the LGE transplants were intermediary.

Consistent with the arrival of migratory interneurons into the cortex after E12.5 (Anderson et al., 1997b), the percentage of GABA-expressing cells among the cortical donor cells increased from E12.5 (1.2 \pm 0.6\%) (SEM) to E14.5 (7.0 $\pm 3.5 \%)$ and E16.5

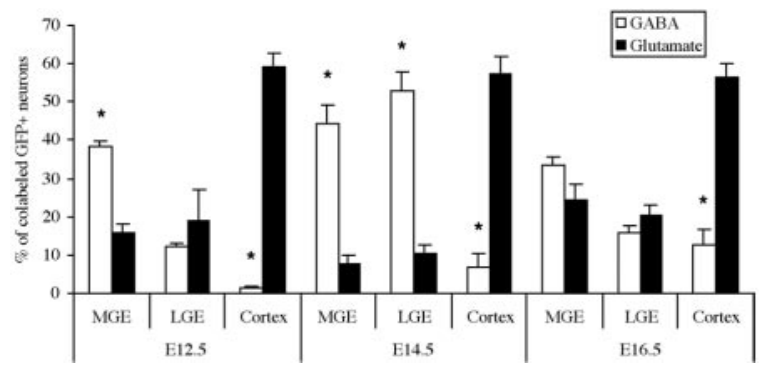

Figure 3. GABA and glutamate expression by transplanted donors from the MGE, LGE, or neocortex after 14 DIV. The percentages of GFP + donor cells with neuronal morphology and that also label for GABA or glutamate are plotted for the three progenitor domains dissected early (E12.5), mid (E14.5), and late (E16.5) in cortical neurogenesis. ${ }^{*} p<0.04$; paired $t$ test.

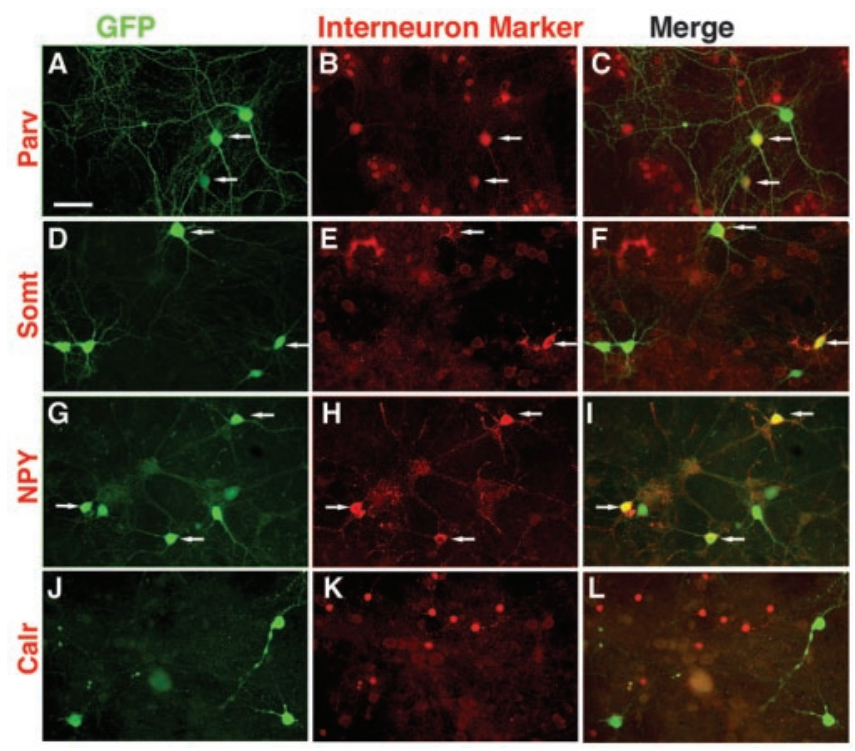

Figure 4. Transplanted progenitors from the MGE give rise to distinct interneuron subtypes. In this experiment the E14.5 MGE donor cells were plated onto neonatal cortex feeders and cultured for 2 weeks (4 weeks in the case of parvalbumin). Each set of three panels shows identical fields, the left side of which shows GFP expression by the donor cells. The middle panels show expression of the interneuron subtype markers parvalbumin (Parv; $B)$, somatostatin (Somt; $E$ ), neuropeptide Y (NPY; $H$ ), and calretinin (Calr; $K)$. The panels on the right side show the merged images. Colabeling is present between some of the MGE donor cells and Parv, Somt, and NPY; however, MGE donors do not colabel for calretinin. Scale bar, $50 \mu \mathrm{m}$.

$(12.7 \pm 4 \%)$. Similar results have been reported recently using a low-density culture system (Yung et al., 2002). These experiments provide further evidence that progenitor domains along the dorsal-ventral axis of the telencephalon have differential potential for generating neurotransmitter phenotypes (Wilson and Rubenstein, 2000; He et al., 2001) and suggest that neuronal subtype fates have not been fundamentally altered by the transplantation procedure. Because E14.5 and E16.5 cortical donors derive exclusively from the proliferative zone (Fig. 2, schema), however, and because very few of the cortical donors from E16.5 express somatostatin or parvalbumin (see Fig. 5), the increased percentage of GABA + cortical donors from later ages may represent a cortically derived interneuron subtype or a tissue-culture artifact.

The MGE gives rise to parvalbumin + and to somatostatin+ but to few calretinin-expressing interneurons

We then compared the potential of telencephalic progenitor domains to give rise to neurochemically defined interneuron subtypes. Across the primary range of cortical plate neurogenesis 


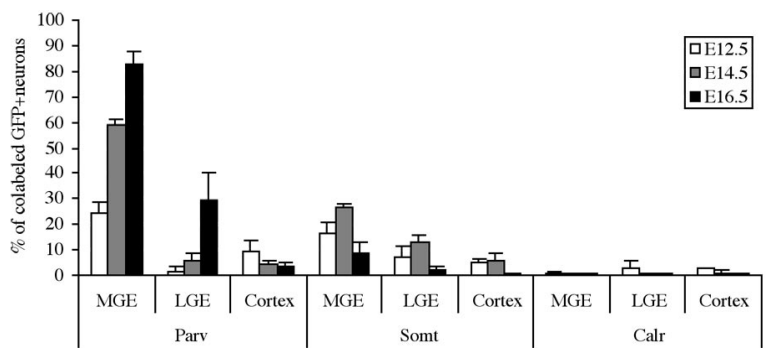

Figure 5. Parvalbumin, somatostatin, and calretinin expression by transplanted proliferative zone cells from the MGE, LGE, or neocortex. Parvalbumin labeling was examined after 28 DIV; somatostatin and calretinin labeling was examined after 14 DIV. The percentages of GFP+ donor cells with neuronal morphology and that also label for these markers of interneuron subgroups are plotted for progenitor domains dissected early (E12.5), mid (E14.5), and late (E16.5) in cortical neurogenesis. Statistical analysis by ANOVA revealed significant effects of area on the percentage of transplanted neurons expressing parvalbumin ( $p<0.003$ for each age) and somatostatin ( $p<0.001$ at E14.5 only)

(E12.5-E16.5), a high percentage of the surviving neurons from MGE transplants expressed parvalbumin or somatostatin $(\sim 50$ vs $25 \%$, respectively) (Figs. 4,5$)$. Few of these subtypes were generated by LGE progenitors at E12.5 or E14.5, although 30\% of the neurons from E16.5 donor LGEs expressed parvalbumin. This number may reflect migratory cells from the MGE moving through the proliferative zone of the LGE (Anderson et al., 2001), as well as parvalbumin-containing interneurons normally destined for the olfactory bulb (Kosaka et al., 1994). Few donor neurons from either the preoptic area (data not shown) or cortex express the interneuron subtype markers (Figs. 4, 5).

Because only $45 \%$ of E14.5 MGE donors express GABA after 14 DIV (Fig. 3), yet $\sim 60 \%$ of MGE donors express parvalbumin after 28 DIV (Fig. 5), we reexamined GABA labeling with GFP, parvalbumin, and somatostatin at this age. After $28 \mathrm{DIV}, 85.0 \pm$ $1.8 \%$ (447 of 523 total) of MGE donors expressed GABA, and $21.2 \pm 0.8 \%$ (54 of 254 total) expressed somatostatin. Of the double-labeled Pv-GFP-expressing cells, $85.2 \pm 1.7 \%$ (151 of 178 total) also expressed GABA. Of the somatostatin-GFP-labeled cells, $96.6 \pm 1.7 \%$ (52 of 54 total) also labeled for GABA. These results raise the possibility that $\mathrm{Pv}$-fated interneurons, which do not express Pv at 14 DIV, likewise do not express detectable levels of GABA at this time.

In marked contrast to the potential for donor neurons from the MGE to express parvalbumin or somatostatin, very few calretinin-expressing cells were generated by the MGE transplants over the E12.5-E16.5 age range (Figs. 4, 5). Combined with the findings from primary cultures of $N k \times 2.1$ mutants, these results strongly suggest that the cortical interneuron subtypes expressing parvalbumin or somatostatin indeed derive primarily from the MGE, whereas the calretinin-expressing interneurons do so rarely.

Finding that MGE transplants give rise to the same interneuron subgroups that are missing in the primary cultures from the $N k \times 2.1$ mutants provides a method for determining whether loss of $N k \times 2.1$ alters the specification or the migration of these subgroups. Normal patterning of the MGE in the Nkx2.1 mutants is abolished in favor of genes normally expressed in the LGE (Sussel et al., 1999). This finding suggests that the loss of somatostatinand parvalbumin-expressing subgroups belies a function of $N k \times 2.1$ in the specification of these cells. To test this hypothesis, the Nkx2.1 mutants were bred into the GFP-expressing mouse line, and the MGE of mutant or wild-type embryos was transplanted onto cortical feeders. Unlike the controls, Nkx2.1-/- mutant donors at E12.5 or E15.5 did not give rise to somatostatin-, NPY-, or parvalbumin-expressing interneurons from donors at either age, suggesting that abnormal specification, and not migration, is the mechanism for losses of these subtypes in the cortices of $N k \times 2.1$ mutants.

\section{The LGE but not MGE gives rise to DARPP32+ neurons}

The fact that a large number of cells from the LGE donors express GABA after transplantation, but relatively few express interneuron markers, raises the question of the identity of these transplanted cells. Previous reports have suggested that the LGE gives rise primarily to striatal medium-spiny neurons (Deacon et al., 1994; Stenman et al., 2003), which are GABAergic projection neurons that also express the phosphoprotein DARPP32 (dopamine- and cAMP-regulated neuronal phosphoprotein) (Anderson and Reiner, 1991). Indeed, 27\% (45 of 162 GFP+ neurons; dissected at E14.5) of LGE donors expressed DARPP32 after 1 week in culture on cortical feeder cells (Fig. 6). Interestingly, only $6.4 \%$ (24 of 377) of LGE donors expressed DARPP32 after culturing on striatal feeders, possibly because of the reduced availability of trophic support from cortical projection neurons. In marked contrast to the LGE donors, no MGE donors express DARPP32 when cultured on either cortex or striatum (cortex feeder, 0 of 212 GFP + neurons; striatal feeder, 0 of 493). The differential potential of MGE or LGE progenitors to express DARPP32 is consistent with the notion that specification occurs within the proliferative zone, before migration.

\section{Birth dating of calretinin-expressing cortical interneurons} As shown in Figures 1, 4, and 5, small bipolar calretininexpressing interneurons do not appear to derive from the MGE, LGE, or cortex during the age range of primary cortical neurogenesis. To determine the origin of these interneurons, we first sought to determine the age at which they exit the cell cycle in vivo. To label a large cohort of dividing cells on E12.5, E14.5, E16.5, E18.5, and P1, injections of the S-phase marker BrdU (50 $\mathrm{mg} / \mathrm{kg}$ ) were made $2 \mathrm{hr}$ apart for $8 \mathrm{hr}$, and cryosections from animals at P25 were labeled for calretinin and BrdU. As expected, the multiple injections of BrdU, which can be detected at decreasing levels in several subsequent cycles, labeled many cells in cor-
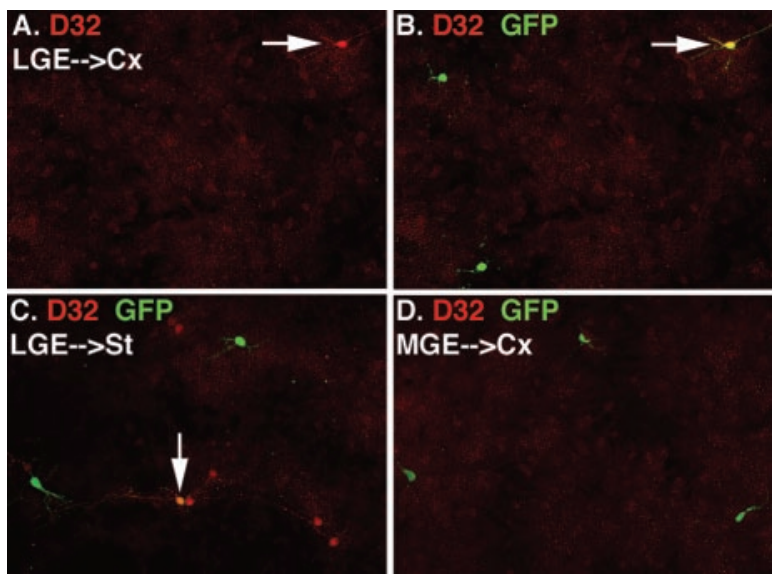

Figure 6. DARPP32 expression in neurons from E14.5 LGE but not MGE. $A, B$, The same field from an experiment in which LGE donors from E14.5 embryos were cultured for 1 week on a cortical feeder layer. The only DARPP32 + cell (arrow) in $A$ is a LGE donor cell as indicated by colabeling for DARPP32 and GFP in B. C, LGE cells cultured on striatal feeders can also express DARPP32 (arrow). In contrast to cells from the LGE, no MGE donor cells express DARPP32 when cultured on cortex (as in $D$ ) or on striatum (data not shown). 
E12.5
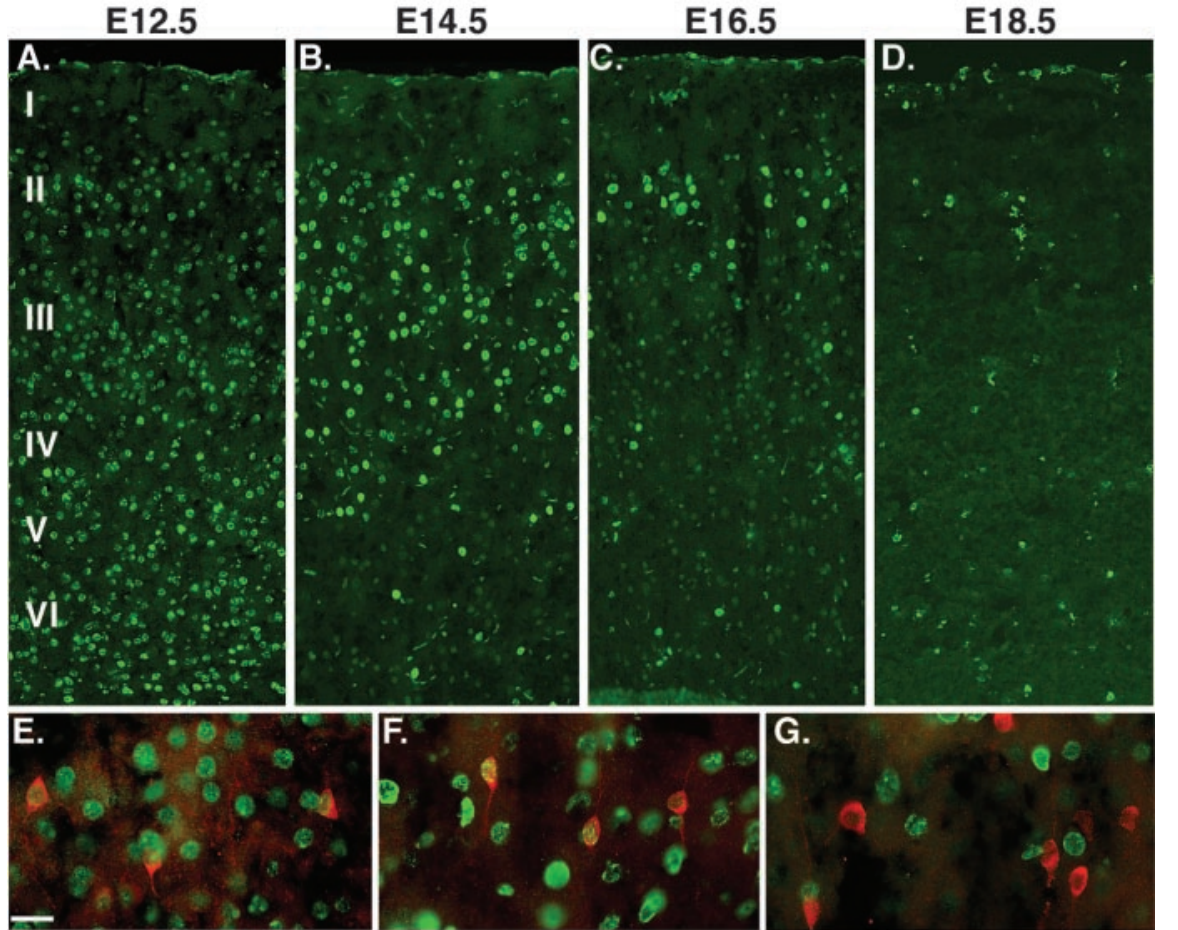

Figure 7. Birth dating of calretinin-expressing cortical interneurons. $A-D$, Low-magnification views of BrdU staining in the somatosensory cortex of animals that received five injections of BrdU $(50 \mathrm{mg} / \mathrm{kg}) 2 \mathrm{hr}$ apart at E12.5 $(A), \mathrm{E} 14.5(B), \mathrm{E} 16.5(D)$, or E18.5 (D).E, F, High-magnification views of calretinin (red) and BrdU (green) labeling in layer II from animals that received E12.5 $(E)$, E14.5 $(F)$, or E16.5 $(G)$ injections. Most of the calretinin-expressing interneurons have a bipolar morphology similar to that seen in vitro and are labeled by BrdU injections at E12.5 (79\%) or E14.5 (70\%) but rarely later (only 1.8\% at E16.5, and essentially none from injections at E18.5 or P1). Scale bar, $20 \mu \mathrm{m}$.

tical layers II-VI after the E12.5 injections, although the most strongly labeled cells resided in the deeper cortical layers (Fig. $7 A$ ). E14.5 and E16.5 injections (Fig. $7 B, C$ ) labeled increasingly superficial cells, whereas the E18.5 (Fig. 7D) and P1 (data not shown) injections weakly labeled scattered cells, suggestive of glia that are thought to be generated late in gestation and continue to divide postnatally (Bayer and Altman, 1991; Levers et al., 2001).

Colabeling for calretinin + and BrdU+ cells clearly demonstrated that most calretinin-expressing cells are born at or after E14.5 and before E16.5. At E12.5 a total of 1125 of 1425 calretinin + cells also labeled for BrdU (79\%). At E14.5 this total was 962 calretinin $+/$ BrdU + of 1366 calretinin $+(70 \%)$. That a similarly high number of cells were labeled by BrdU E14.5 injections as at E12.5 suggests that most of the calretinin + cells are in fact born after E14.5. Injections of BrdU at E16.5 labeled only 29 of 1603 calretinin-expressing cells (1.8\%). Double labeling for calretinin and BrdU from the E18.5 and P1 injections was negligible. In summary, these results are consistent with reports that cortical interneurons are generally born over the same age range as cortical projection neurons (Fairén et al., 1986; Peduzzi, 1988).

\section{Donor neurons from the caudal ganglionic eminence express calretinin}

Because calretinin-expressing cortical interneurons become postmitotic between E12.5 and E16.5 and do not appear to derive from the preoptic area, MGE, LGE, or cortex, we extended our analysis to other potential telencephalic sources. The CGE was selected because it is a source of interneuron migration into the neocortex (Anderson et al., 2001; Nery et al., 2002; Ang et al.,
2003). In addition, the CGE is less affected in the Nkx2.1 mutant than the MGE (Nery et al., 2001), including tangential migration of Dlx2-expressing cells into the cortex (Nery et al., 2003).

In remarkable contrast to results from the MGE, LGE, or cortex, calretinin was expressed by almost 30\% of the donor neurons from E14.5 CGE cultured on cortical feeder cells (Fig. 8). This result was time dependent, because $<5 \%$ of E12.5 or E16.5 CGE donors expressed calretinin (Fig. $8 E$ ). The number of GFP + neurons from CGE donors detected per well after 14 DIV, a number that reflects both proliferation and survival of the donor cells, was actually higher for E12.5 donors ( $141 \pm 10$ neurons per well) and E16.5 donors (121 \pm 18 neurons per well) than for donors from E14.5 (91 \pm 7 neurons per well). This result suggests that E14.5 CGE donors do not simply survive or proliferate more than those at the other ages. Conceivably, the E14.5 donors are distinct from donors of the other ages because of an intrinsic difference in their response to FGF2.

At E14.5, retrobulbar area donors, dissected from the ventrolateral wall of the lateral ventricle rostral to the septal area and just caudal to the olfactory bulb, also give rise to calretinin-expressing cells (data not shown). Although immunohistochemical analysis of GABA, DLX1, or calbindin expression is suggestive of a migration from this area into the overlying cerebral cortex (Meyer et al., 1998; Anderson et al., 1999; Ang et al., 2003), efforts to demonstrate a robust migration from the retrobulbar area to the overlying cortex in explant cultures have been unsuccessful (S. A. Anderson, unpublished data). Alternatively, transplanted retrobulbar cells may normally be destined for the olfactory bulb. Transplants from the same area as well as the anterior SVZ of the LGE, and the SVZ of the cortex, also give rise to calretininexpressing cells at E18.5, P1, and P5 (data not shown); however, these cells may again be normally destined for the olfactory bulb (Luskin, 1993; Lois and Alvarez-Buylla, 1994; Suzuki and Goldman, 2003), and the timing of these transplantations does not correlate with the in vivo birth-dating data for most cortical calretinin + interneurons (Fig. 7).

Loss of calretinin-expressing bipolar interneurons in primary cortical cultures from $D l \times 1 / 2-/-$ mutants

Mutants lacking both $D l x 1$ and $D l \times 2(D l \times 1 / 2)$ have a $\sim 75 \%$ loss of cortical GABA-expressing neurons at P0 and have minimal migration from the ganglionic eminences to the cortex in explant cultures (Anderson et al., 1997b, Anderson et al., 2001). Thus we were interested in using $D l \times 1 / 2-/-$ primary cortical cultures to determine the subtype identity of the remaining $25 \%$ of GABAexpressing cortical neurons. Surprisingly, although NPY- and somatostatin-expressing interneurons were reduced in these cultures (Fig. 9E), calretinin-expressing interneurons were nearly absent (Fig. 9B). Unlike the small bipolar calretinin-expressing neurons that are found in transplants from the CGE (Fig. 8), the remaining calretinin-expressing neurons in the $D l \times 1 / 2$ mutant 
cultures were large and generally unipolar (Fig. 9C). Calretininexpressing cells with this morphology in vitro have previously been identified as Cajal-Retzius cells (Pappas and Parnavelas, 1998), neurons that derive primarily from the cortical preplate (Marin-Padilla, 1998; Hevner et al., 2003) and that appear to be unaffected in the Dlx1/2 mutants (Anderson et al., 1997b). To further characterize these cells, cultures were immunolabeled for calretinin and reelin, a glycoprotein strongly expressed in CajalRetzius cells (Alcantara et al., 1998; Meyer et al., 1999). Nearly all of the remaining calretinin-expressing cells in the $D l \times 1 / 2-/-$ cultures strongly expressed reelin (Fig. 9D). These results suggest that calretinin-expressing interneurons are more dependent on $D l \times 1 / 2$ function than are somatostatin- or NPY-expressing interneurons. They also imply and that, in fact, the interneuron migration phenotype in these mutants may be "leaky" for MGEderived interneurons, as suggested by the small amount of cortical expression of Lhx6 (Anderson et al., 2002).

The dependence of calretinin-expressing interneurons on $D l x 1$ and $D l \times 2$ is surprising in light of evidence that these neurons are generated by transplants from the E14.5 CGE, but rarely by the E12.5-E16.5 MGE, LGE, or cortex (including the Dlxexpressing cortical SVZ), each of which also express Dlx1 and Dlx2 (Bulfone et al., 1993; Anderson et al., 2001; Nery et al., 2003). In addition to their dependence on Dlx genes, the calretinin-expressing subgroup is distinct from the other interneuron subtypes on the basis of their ability to proliferate in culture in response to FGF2 (Pappas and Parnavelas, 1998; Xu and Anderson, unpublished data). In fact, a substantial number of cells derived from the CGE divide during the first several days in culture, including many of those that go on to express calretinin (Fig. $8 F, G$ ). This result suggests that $D l x 1$ or $D l \times 2$, or both, may be required for CGE progenitors to differentiate into bipolar calretinin-expressing interneurons in response to specific environmental factors. In support of a general requirement of $D l x 1$ and Dlx2 for generating interneurons in vitro, at E16.5, 75\% of clonally derived FGF2 expanded cortical cultures generate GABA-expressing neurons from wild types, whereas $<5 \%$ do so when derived from $D l \times 1 / 2-/-$ cortex (Yung et al., 2002). The ability of progenitors from a $D l x$-expressing domain to divide after transplantation does not by itself result in calretinin specification, however, because substantial numbers of MGE and LGE donors also divide the first night in vitro (Fig. 8G), yet these donors very rarely give rise to calretinin-expressing cells (Fig. 5).

\section{Discussion}

Parvalbumin- and somatostatin-expressing cortical

\section{interneurons derive primarily from the MGE}

The presence of multiple potential sources of cortical interneurons, including the MGE, LGE, CGE, retrobulbar area, and cortical SVZ, raises the possibility that distinct subtypes derive from distinct sources (for review, see Xu et al., 2003). The Nkx2.1 mutant, in which no morphologically distinct MGE forms and genetic markers of the MGE have been replaced by those of the LGE (Sussel et al., 1999), should provide an excellent model for assessing MGE-derived interneuron subtypes. Indeed, the somatostatin-expressing subgroup is essentially absent in the cortices of these mutants at E18.5 (Anderson et al., 2001). To determine whether interneuron subtypes that begin expression postnatally are also affected in these mutants, primary cultures were made from E18.5 Nkx2.1-/- mutants and their wild-type littermates. Not only were somatostatin- and NPY-expressing interneurons absent from these cultures in the mutants, parvalbuminexpressing interneurons were also absent (Fig. 1). These results provide evidence that parvalbumin- and somatostatin-expressing interneuron subgroups are derived from $N k \times 2.1+$ domains of the MGE.

To directly assess the potential for distinct telencephalic domains to give rise to subgroups of cortical interneurons, we have used a transplantation assay in vitro. Consistent with previous studies (He et al., 2001; Yung et al., 2002), progenitors from the MGE or LGE were far more likely than cortical progenitors to express GABA, whereas cortical progenitors tended to express glutamate (Fig. 3). The very low percentage of transplanted cortical cells that express GABA from E12.5 donors supports the strength of this approach to assess cell fate in a relatively normal environmental context. Because $12 \%$ of donors from the E16.5 cortical proliferative zone express GABA, whereas few of them express calretinin, somatostatin, or parvalbumin (Fig. 5), the results of this study also lend tentative support for the existence of a cortically derived interneuron subtype that does not fall within the $85 \%$ of cortical interneurons expressing these markers (see also below). Alternatively, the culture conditions, including the addition of FGF2 after the donor's first day in vitro, may have resulted in the "ventralization" of some cortical progenitors (Gabay et al., 2003).

Although both the LGE and the MGE gave rise to large numbers of GABA-expressing neurons in the transplantation assay, there was a striking specificity for the MGE but not LGE to give rise to parvalbumin-expressing neurons (Figs. 4, 5). In addition, many more donor neurons from the MGE than LGE expressed somatostatin or NPY, whereas only LGE donors expressed DARPP32, a marker of striatal medium spiny neurons (Fig. 6). These results support previous findings indicating that the MGE is the primary subcortical source of cortical interneurons (Wichterle et al., 1999; Anderson et al., 2001; Wichterle et al., 2001). It remains unclear whether a relatively rare interneuron subtype derives from the LGE or whether the GABA-expressing neurons from the LGE transplants were actually striatal projection neurons (Deacon et al., 1994; Anderson et al., 1997a; Stenman et al., 2003) or olfactory bulb interneurons (Luskin, 1993; Lois and Alvarez-Buylla, 1994; Stenman et al., 2003) surviving on the cortical feeder cells.

One caveat regarding the transplantation results is that most neurochemical markers of cortical interneurons are also expressed by striatal interneurons (Kubota and Kawaguchi, 1994; Kawaguchi et al., 1995) and probably share the same progenitor cells within the MGE (Marin et al., 2000). Thus these findings do not necessarily distinguish between MGE donor neurons that had a truly cortical fate and those that would have settled in the striatum. In addition, colabeling for parvalbumin and GABA, measured at $\sim 89 \%$ within the cortical feeders and $85 \%$ for GFP+/parvalbumin +-expressing MGE donors, falls below that generally reported ex vivo (nearly 100\%) (DeFelipe, 1993). This discrepancy may reflect low GABA production by some parvalbumin-expressing interneurons in these cultures or the presence of a GABA-negative parvalbumin-expressing cell type that is not present in vivo. Comparison of the transplantation results with those from cultures of $N k \times 2.1$ mutant cortex, however, strongly supports the notion that cortical interneurons expressing parvalbumin or somatostatin derive primarily from the MGE, whereas those that express calretinin do not (see below).

\section{Implications for the specification of MGE-derived cortical interneurons}

Identification of distinct origins of distinct interneuron subtypes has important implications for identifying the mechanisms 


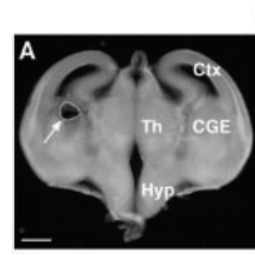

E

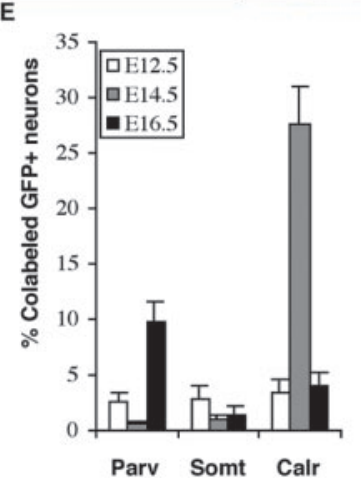

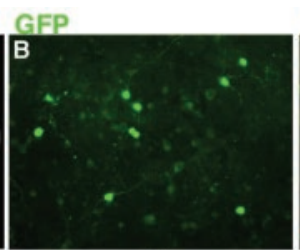

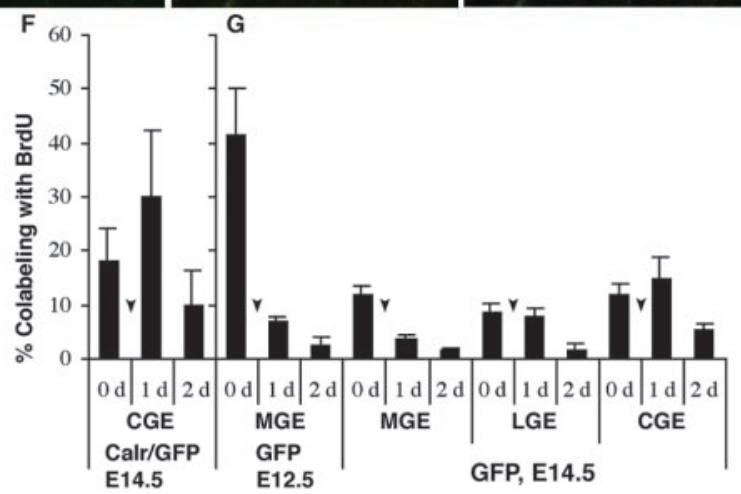

Figure 8. Transplanted progenitors from the E14.5 CGE give rise to calretinin-expressing cells. $A$, The region of (GE that was dissected from a 300- $\mu \mathrm{m}$-thick coronal section at E14.5. This region is dorsal to the Nkx2.1-expressing domain (Nery et al., 2002). Many of the GFP plus CGE donor cells $(B)$ colabel for calretinin ( $C$. These colabeled neurons do not also label for reelin (D) (reelin triple labeled with GFP and calretinin in a total of 6 of 201 cells from 3 separate experiments). Graph in $E$ shows that CGE donors generate calretinin-expressing (Calr) cells primarily at E14.5 and that relatively few parvalbumin (Parv)- or somatostatin (Somt)expressing neurons are generated by these transplants. $F$, Many of the calretinin + donor neurons from CGE were generated by progenitors that proliferated after transplantation. The graph shows the percentage of GFP +-calretinin + neurons from the E14.5 (GE that proliferated (triple labeled with BrdU) during the first, second, or third DIV. The rise in triple-labeled cells between the first and second DIV results from the addition of FGF2 to the medium at the start of 2 DIV as indicated by arrowheads. The graph in $G$ shows BrdU incorporation by GFP + donor neurons from the MGE at E12.5 and from the MGE, LGE, or CGE at E14.5. Despite high levels of proliferation during the first day in vitro for MGE donors at E12.5 and modest initial levels of proliferation for MGE or LGE donors at E14.5, only the CGE donors give rise to large numbers of calretinin + neurons. Ctx, Cortex, Th, thalamus; Hyp, hypothalamus; Calr, calretinin; Rln, reelin. Scale bars: $A, 500 \mu \mathrm{m} ; B-D, 50 \mu \mathrm{m}$. for generating interneuron diversity. Both the absence of parvalbumin- or somatostatin-expressing interneurons in primary cortical cultures of $N k x 2.1-/-$ mutants and the lack of these markers in transplants of the MGE-like region from the $N k \times 2.1-/-$ mutants indicate that $\mathrm{Nkx} 2.1$ function is required for the specification of these subtypes. Linkage of this transcription factor to the mature fates of interneuron subgroups provides the opportunity to initiate the process of identifying a transcriptional code for the specification of these subgroups. Upstream of $N k \times 2.1$, Shh secretion from the prechordal mesoderm is normally required for the formation of the ventral forebrain (Ericson et al., 1995; Shimamura et al., 1995; Chiang et al., 1996; Kohtz et al., 1998), and the homeodomain gene Six3 confers the ability of neural tissue to express Nkx2.1 in response to Shh (Kobayashi et al., 2002).

Putative downstream targets of Nkx2.1, which are absent in the null mutants and may also be involved in interneuron specification, include the lim-homeodomain genes $L h x 6$ and $L h x 7 / 8$ (Sussel et al., 1999; Zhao et al., 2003). Lhx7/8 function is required for the development of telencephalic cholinergic neurons (Zhao et al., 2003). Lhx6 is expressed in what appears to be a stream of cells migrating from the MGE into the neocortex (Grigoriou et al., 1998; Lavdas et al., 1999), and its cortical expression is greatly reduced in the $D l \times 1 / D l \times 2$ mutants in which interneuron migration to the cortex is impaired (Anderson et al., 2001).

Distinct origins of calretinin-expressing cortical interneurons Regardless of the mechanism for specifying the MGE-derived interneuron subtypes, the evidence presented in this paper strongly sug- gests that calretinin-expressing interneurons have origins that are distinct from the other subgroups. In contrast to the parvalbuminor somatostatin-expressing interneurons, calretinin-expressing interneurons in primary cortical cultures were not affected in the Nkx2.1 mutants (Fig. 1). Moreover, calretinin was very rarely expressed by donor neurons from the MGE, LGE, or cortex from E12.5 to E16.5 (Fig. 5). These findings correlate with several studies in vivo that also found that few calretinin-expressing cortical interneurons derive from the MGE (Wichterle et al., 2001; Anderson et al., 2002; Valcanis and Tan, 2003). On the other hand, calretinin is frequently expressed by donor neurons transplanted from the CGE (Fig. 8). Importantly, this expression occurred primarily in CGE donors transplanted at E14.5, a finding that correlated well with BrdU birth-dating studies (Fig. 7). The molecular difference among E12.5, E14.5, and E16.5 CGE progenitors that is responsible their differential generation of calretinin-expressing cells remains to be determined.

Morphologically, the CGE is essentially a caudal extension of the fused MGE and LGE that protrudes into the lateral ventricle at the level of the mid to caudal thalamus. Molecularly, in some respects it shares more in common with the LGE than MGE. First, it expresses high levels of the transcription factor Gsh2 (Nery et al., 2002; Corbin et al., 2003). Second, SFRP2, which is expressed in a narrow domain between the cortex and the LGE, is expressed in a far broader region of the caudal CGE (Kim et al., 2001; Muzio et al., 2002). Third, Nkx2.1 is expressed only in the ventral portion of the more rostral CGE, within the lateral wall of the ventral extension of the ventricle rather than the region that protrudes into the ventricle (Nery et al., 2002). Finally, evidence from analysis of $N k \times 2.1$ or Gsh2 mutants finds milder effects on the CGE versus the MGE or LGE (Nery et al., 2002). The relative lack of CGE patterning abnormalities in the $N k \times 2.1$ mutant correlates with the sparing of calretinin-expressing interneurons in the cultures of Nkx2.1 mutant cortex (Fig. 1).

At E14.5, the relative specificity of the CGE for calretininexpressing cells versus the other interneuron subtypes was surprising in light of a recently published work that studied the fates of CGE neurons transplanted in vivo (Nery et al., 2002). This study found that many CGE donors differentiated into layer $\mathrm{V}$ neurons with multipolar morphologies more consistent with somatostatin- or parvalbumin-expressing interneurons, and relatively few had bipolar morphology; however, donors came from embryos dissected at E13.5, which appears to be before generation of most calretinin-expressing interneurons (Fig. 7). In addition, donor material appeared to include both the more dorsal, strongly Gsh2-expressing portion of the CGE and the more ventral $N k \times 2.1$-expressing region. In our study only the $N k \times 2.1$-negative part of the CGE was transplanted (Fig. $8 A$ ), which may explain the increased specificity for calretinin-positive interneurons.

It remains to be determined how molecular differences in the CGE and LGE produce such dramatic differences in cell fate. One 
possibility is that the CGE and LGE can both generate calretinin-expressing interneurons, although differential guidance cues direct CGE cells dorsally into the cortex, whereas those from the LGE primarily migrate rostrally, proliferating within the rostral migratory stream route to the olfactory bulb. In fact, ER81, a transcription factor that distinguishes the dorsal LGE that produces olfactory bulb interneurons from the ventral LGE that makes striatum (Yun et al., 2001; Stenman et al., 2003), is also expressed in the region of the CGE that was transplanted in these studies (Xu and Anderson, unpublished data).

\section{Lack of evidence for a large cortical} origin of cortical interneurons in mice The results of this study, in contrast to recent reports on human development (Letinic et al., 2002; Rakic and Zecevic, 2003), do not support the origin of a large number of cortical interneurons within the mouse cortex itself. Those that express calretinin, parvalbumin, or somatostatin, which together comprise $>80 \%$ of cortical interneurons (Gonchar and Burkhalter, 1997; Tamamaki et al., 2003), appear to derive from subcortical sources. This contention is supported by the finding that virtually all cortical interneurons in the mouse derive from a Dlx5/6-expressing lineage (Stuhmer et al., 2002) and are not part of an Emx1-expressing lineage (Iwasato et al., 2000; Gorski et al., 2002). Moreover, subcortically derived Dlxexpressing cells that migrate from the MGE (Polleux et al., 2002; $\mathrm{Xu}$ et al., 2003) or CGE (Xu and Anderson, unpublished data) to the cortex in explant cultures are overwhelmingly postmitotic. Although proliferating $D l x$-expressing cells are present within the mouse cortical SVZ postnatally (Anderson et al., 2001), this occurs after most calretinin-expressing interneurons become postmitotic (Fig. 7), and the fate of these cells is probably restricted to cortical glia or to interneurons of the olfactory bulb (Marshall and Goldman, 2002; Suzuki and Goldman, 2003). Finally, injections of tritiated thymidine into the cortical VZ-SVZ of P1 ferrets, which generate the same cortical layers as an E15 or E16 mouse, do not label calretinin + or other cortical interneurons in vivo (Anderson et al., 2002).

In summary, an in vitro transplantation assay and analysis of Nkx2.1 mutants provide evidence that somatostatin- and parvalbumin-expressing interneurons derive primarily from the MGE, whereas calretinin-expressing interneurons appear to derive primarily from the CGE. Through transplants of telencephalic donor cells from mutant strains, or from cultured explants that have been subjected to experimental manipulations, the in vitro assay is well suited to determining factors responsible for the specification of neuronal subtypes that only become identifiable in the postnatal cerebral cortex.

\section{References}

Alcantara S, de Lecea L, Del Rio JA, Ferrer I, Soriano E (1996) Transient colocalization of parvalbumin and calbindin D28k in the postnatal cerebral cortex: evidence for a phenotypic shift in developing nonpyramidal neurons. Eur J Neurosci 8:1329-1339.

Alcantara S, Ruiz M, D’Arcangelo G, Ezan F, de Lecea L, Curran T, Sotelo C, Soriano E (1998) Regional and cellular patterns of reelin mRNA expres- sion in the forebrain of the developing and adult mouse. J Neurosci 18:7779-7799.

Anderson KD, Reiner A (1991) Immunohistochemical localization of DARPP-32 in striatal projection neurons and striatal interneurons: implications for the localization of D1-like dopamine receptors on different types of striatal neurons. Brain Res 568:235-243.

Anderson S, Mione M, Yun K, Rubenstein JLR (1999) Differential origins of projection and local circuit neurons: role of Dlx genes in neocortical interneuronogenesis. Cereb Cortex 9:646-654.

Anderson SA, Qiu M, Bulfone A, Eisenstat DD, Meneses J, Pedersen R, Rubenstein JL (1997a) Mutations of the homeobox genes Dlx-1 and Dlx-2 disrupt the striatal subventricular zone and differentiation of late born striatal neurons. Neuron 19:27-37.

Anderson SA, Eisenstat DD, Shi L, Rubenstein JL (1997b) Interneuron migration from basal forebrain to neocortex: dependence on Dlx genes. Science 278:474-476.

Anderson SA, Marin O, Horn C, Jennings K, Rubenstein JL (2001) Distinct cortical migrations from the medial and lateral ganglionic eminences. Development 128:353-363.

Anderson SA, Kaznowski CE, Horn C, Rubenstein JL, McConnell SK (2002) Distinct origins of neocortical projection neurons and interneurons in vivo. Cereb Cortex 12:702-709.

Ang Jr ES, Haydar TF, Gluncic V, Rakic P (2003) Four-dimensional migratory coordinates of GABAergic interneurons in the developing mouse cortex. J Neurosci 23:5805-5815.

Bayer SA, Altman J (1991) Neocortical development. New York: Academic.

Bellion A, Wassef M, Metin C (2003) Early differences in axonal outgrowth, cell migration and GABAergic differentiation properties between the dorsal and lateral cortex. Cereb Cortex 13:203-214.

Bulfone A, Puelles L, Porteus MH, Frohman MA, Martin GR, Rubenstein JLR (1993) Spatially restricted expression of $D l x-1$, Dlx-2(Tes-1), Gbx-2, and Wnt-3 in the embryonic day 12.5 mouse forebrain defines potential transverse and longitudinal segmental boundaries. J Neurosci 13:3155-3172.

Cauli B, Audinat E, Lambolez B, Angulo MC, Ropert N, Tsuzuki K, Hestrin S, Rossier J (1997) Molecular and physiological diversity of cortical nonpyramidal cells. J Neurosci 17:3894-3906.

Cavanagh ME, Parnavelas JG (1988) Development of somatostatin immunoreactive neurons in the rat occipital cortex: a combined immunocytochemical-autoradiographic study. J Comp Neurol 268:1-12.

Cavanagh ME, Parnavelas JG (1989) Development of vasoactive-intestinalpolypeptide-immunoreactive neurons in the rat occipital cortex: a combined immunohistochemical-autoradiographic study. J Comp Neurol 284:637-645.

Chan CH, Godinho LN, Thomaidou D, Tan SS, Gulisano M, Parnavelas JG 
(2001) Emx1 is a marker for pyramidal neurons of the cerebral cortex. Cereb Cortex 11:1191-1198.

Cherubini E, Conti F (2001) Generating diversity at GABAergic synapses. Trends Neurosci 24:155-162.

Chiang C, Litingtung Y, Lee E, Young KE, Corden JL, Westphal H, Beachy PA (1996) Cyclopia and defective axial patterning in mice lacking Sonic hedgehog gene function. Nature 383:407-413.

Corbin JG, Nery S, Fishell G (2001) Telencephalic cells take a tangent: nonradial migration in the mammalian forebrain. Nat Neurosci 4 [Supp 1]:1177-1182.

Corbin JG, Rutlin M, Gaiano N, Fishell G (2003) Combinatorial function of the homeodomain proteins $\mathrm{Nkx} 2.1$ and Gsh2 in ventral telencephalic patterning. Development 130:4895-4906.

Deacon TW, Pakzaban P, Isacson O (1994) The lateral ganglionic eminence is the origin of cells committed to striatal phenotypes: neural transplantation and developmental evidence. Brain Res 668:211-219.

DeFelipe J (1993) Neocortical neuronal diversity: chemical heterogeneity revealed by colocalization studies of classic neurotransmitters, neuropeptides, calcium-binding proteins, and cell surface molecules. Cereb Cortex 3:273-289.

DeFelipe J (1999) Chandelier cells and epilepsy. Brain 122:1807-1822.

Ericson J, Muhr J, Placzek M, Lints T, Jessell TM, Edlund T (1995) Sonic hedgehog induces the differentiation of ventral forebrain neurons: a common signal for ventral patterning within the neural tube. Cell 81:747-756.

Fagiolini M, Hensch TK (2000) Inhibitory threshold for critical-period activation in primary visual cortex. Nature 404:183-186.

Fairén A, Cobas A, Fonseca M (1986) Times of generation of glutamic acid decarboxylase immunoreactive neurons in mouse somatosensory cortex. J Comp Neurol 251:67-83.

Franklin BJ, Paxinos G (1997) The mouse brain in stereotaxic coordinates. New York: Academic.

Gabay L, Lowell S, Rubin LL, Anderson DJ (2003) Deregulation of dorsoventral patterning by FGF confers trilineage differentiation capacity on CNS stem cells in vitro. Neuron 40:485-499.

Gao WJ, Wormington AB, Newman DE, Pallas SL (2000) Development of inhibitory circuitry in visual and auditory cortex of postnatal ferrets: immunocytochemical localization of calbindin- and parvalbumincontaining neurons. J Comp Neurol 422:140-157.

Gonchar Y, Burkhalter A (1997) Three distinct families of GABAergic neurons in rat visual cortex. Cereb Cortex 7:347-358.

Gorski JA, Talley T, Qiu M, Puelles L, Rubenstein JL, Jones KR (2002) Cortical excitatory neurons and glia, but not GABAergic neurons, are produced in the Emx1-expressing lineage. J Neurosci 22:6309-6314.

Götz M, Williams BP, Bolz J, Price J (1995) The specification of neuronal fate: a common precursor for neurotransmitter subtypes in the rat cerebral cortex in vitro. Eur J Neurosci 7:889-898.

Grigoriou M, Tucker AS, Sharpe PT, Pachnis V (1998) Expression and regulation of Lhx6 and Lhx7, a novel subfamily of LIM homeodomain encoding genes, suggests a role in mammalian head development. Development 125:2063-2074.

Hadjantonakis AK, Gertsenstein M, Ikawa M, Okabe M, Nagy A (1998) Generating green fluorescent mice by germline transmission of green fluorescent ES cells. Mech Dev 76:79-90.

He W, Ingraham C, Rising L, Goderie S, Temple S (2001) Multipotent stem cells from the mouse basal forebrain contribute GABAergic neurons and oligodendrocytes to the cerebral cortex during embryogenesis. J Neurosci 21:8854-8862.

Hevner RF, Neogi T, Englund C, Daza RA, Fink A (2003) Cajal-Retzius cells in the mouse: transcription factors, neurotransmitters, and birthdays suggest a pallial origin. Brain Res Dev Brain Res 141:39-53.

Huang ZJ, Kirkwood A, Pizzorusso T, Porciatti V, Morales B, Bear MF, Maffei L, Tonegawa S (1999) BDNF regulates the maturation of inhibition and the critical period of plasticity in mouse visual cortex. Cell 98:739-755.

Iwasato T, Datwani A, Wolf AM, Nishiyama H, Taguchi Y, Tonegawa S, Knopfel T, Erzurumlu RS, Itohara S (2000) Cortex-restricted disruption of NMDAR1 impairs neuronal patterns in the barrel cortex. Nature 406:726-731.

Jimenez D, Lopez-Mascaraque LM, Valverde F, De Carlos JA (2002) Tangential migration in neocortical development. Dev Biol 244:155-169.

Kawaguchi Y, Kubota Y (1996) Physiological and morphological identification of somatostatin- or vasoactive intestinal polypeptide-containing cells among GABAergic cell subtypes in rat frontal cortex. J Neurosci 16:2701-2715.

Kawaguchi Y, Kubota Y (1997) GABAergic cell subtypes and their synaptic connections in rat frontal cortex. Cereb Cortex 7:476-486.

Kawaguchi Y, Wilson CJ, Augood SJ, Emson PC (1995) Striatal interneurones: chemical, physiological and morphological characterization. Trends Neurosci 18:527-535.

Kim AS, Anderson SA, Rubenstein JL, Lowenstein DH, Pleasure SJ (2001) Pax-6 regulates expression of SFRP-2 and Wnt-7b in the developing CNS. J Neurosci 21:RC132(1-5).

Kimura S, Hara Y, Pineau T, Fernandez-Salguero P, Fox CH, Ward JM, Gonzalez FJ (1996) The T/ebp null mouse: thyroid-specific enhancerbinding protein is essential for the organogenesis of the thyroid, lung, ventral forebrain, and pituitary. Genes Dev 10:60-69.

Kobayashi D, Kobayashi M, Matsumoto K, Ogura T, Nakafuku M, Shimamura K (2002) Early subdivisions in the neural plate define distinct competence for inductive signals. Development 129:83-93.

Kohtz JD, Baker DP, Corte G, Fishell G (1998) Regionalization within the mammalian telencephalon is mediated by changes in responsiveness to Sonic Hedgehog. Development 125:5079-5089.

Kosaka K, Heizmann CW, Kosaka T (1994) Calcium-binding protein parvalbumin-immunoreactive neurons in the rat olfactory bulb. 1. Distribution and structural features in adult rat. Exp Brain Res 99:191-204.

Krimer LS, Goldman-Rakic PS (2001) Prefrontal microcircuits: membrane properties and excitatory input of local, medium, and wide arbor interneurons. J Neurosci 21:3788-3796.

Kubota Y, Kawaguchi Y (1994) Three classes of GABAergic interneurons in neocortex and neostriatum. Jpn J Physiol 44 [Suppl 2]:S145-148.

Kubota Y, Hattori R, Yui Y (1994) Three distinct subpopulations of GABAergic neurons in rat frontal agranular cortex. Brain Res 649:159-173.

Lavdas AA, Grigoriou M, Pachnis V, Parnavelas JG (1999) The medial ganglionic eminence gives rise to a population of early neurons in the developing cerebral cortex. J Neurosci 19:7881-7888.

Letinic K, Zoncu R, Rakic P (2002) Origin of GABAergic neurons in the human neocortex. Nature 417:645-649.

Levers TE, Edgar JM, Price DJ (2001) The fates of cells generated at the end of neurogenesis in developing mouse cortex. J Neurobiol 48:265-277.

Lewis DA (2000) GABAergic local circuit neurons and prefrontal cortical dysfunction in schizophrenia. Brain Res Brain Res Rev 31:270-276.

Lobe CG, Koop KE, Kreppner W, Lomeli H, Gertsenstein M, Nagy A (1999) $\mathrm{Z} / \mathrm{AP}$, a double reporter for cre-mediated recombination. Dev Biol 208:281-292.

Lois C, Alvarez-Buylla A (1994) Long-distance neuronal migration in the adult mammalian brain. Science 264:1145-1148.

Lund JS, Lewis DA (1993) Local circuit neurons of developing and mature macaque prefrontal cortex: Golgi and immunocytochemical characteristics. J Comp Neurol 328:282-312.

Luskin MB (1993) Restricted proliferation and migration of postnatally generated neurons derived from the forebrain subventricular zone. Neuron 11:173-189.

Marin O, Rubenstein JL (2001) A long, remarkable journey: tangential migration in the telencephalon. Nat Rev Neurosci 2:780-790.

Marin O, Anderson SA, Rubenstein JL (2000) Origin and molecular specification of striatal interneurons. J Neurosci 20:6063-6076.

Marin-Padilla M (1998) Cajal-Retzius cells and the development of the neocortex. Trends Neurosci 21:64-71.

Marshall CA, Goldman JE (2002) Subpallial dlx2-expressing cells give rise to astrocytes and oligodendrocytes in the cerebral cortex and white matter. J Neurosci 22:9821-9830.

Meyer G, Soria JM, Martínez-Galán JR, Martín-Clemente B, Fairén A (1998) Different origins and developmental histories of transient neurons in the marginal zone of the fetal and neonatal rat cortex. J Comp Neurol 397:493-518.

Meyer G, Goffinet AM, Fairén A (1999) What is a Cajal-Retzius cell? A reassessment of a classical cell type based on recent observations in the developing neocortex. Cereb Cortex 9:765-775.

Muzio L, DiBenedetto B, Stoykova A, Boncinelli E, Gruss P, Mallamaci A (2002) Emx2 and Pax6 control regionalization of the pre-neuronogenic cortical primordium. Cereb Cortex 12:129-139.

Nery S, Wichterle H, Fishell G (2001) Sonic hedgehog contributes to oligo- 
dendrocyte specification in the mammalian forebrain. Development 128:527-540.

Nery S, Fishell G, Corbin JG (2002) The caudal ganglionic eminence is a source of distinct cortical and subcortical cell populations. Nat Neurosci 5:1279-1287.

Nery S, Corbin JG, Fishell G (2003) Dlx2 progenitor migration in wild type and nkx2.1 mutant telencephalon. Cereb Cortex 13:895-903.

Owens DF, Kriegstein AR (2002) Is there more to GABA than synaptic inhibition? Nat Rev Neurosci 3:715-727.

Pappas IS, Parnavelas JG (1998) Basic fibroblast growth factor promotes the generation and differentiation of calretinin neurons in the rat cerebral cortex in vitro. Eur J Neurosci 10:1436-1445.

Parnavelas JG (2000) The origin and migration of cortical neurones: new vistas. Trends Neurosci 23:126-131.

Peduzzi JD (1988) Genesis of GABA-immunoreactive neurons in the ferret visual cortex. J Neurosci 8:920-931.

Polleux F, Whitford KL, Dijkhuizen PA, Vitalis T, Ghosh A (2002) Control of cortical interneuron migration by neurotrophins and PI3-kinase signaling. Development 129:3147-3160.

Rakic S, Zecevic N (2003) Emerging complexity of layer I in human cerebral cortex. Cereb Cortex 13:1072-1083.

Ramon y Cajal S (1911) Histology of the nervous system. New York: Oxford UP.

Rao SG, Williams GV, Goldman-Rakic PS (2000) Destruction and creation of spatial tuning by disinhibition: GABA(A) blockade of prefrontal cortical neurons engaged by working memory. J Neurosci 20:485-494.

Rogers JH (1992) Immunohistochemical markers in rat cortex: colocalization of calretinin and calbindin-D28k with neuropeptides and GABA. Brain Res 587:147-157.

Schierle GS, Gander JC, D'Orlando C, Ceilo MR, Vogt Weisenhorn DM (1997) Calretinin-immunoreactivity during postnatal development of the rat isocortex: a qualitative and quantitative study. Cereb Cortex 7:130-142.

Shimamura K, Hartigan DJ, Martinez S, Puelles L, Rubenstein JL (1995) Longitudinal organization of the anterior neural plate and neural tube. Development 121:3923-3933.

Stenman J, Toresson H, Campbell K (2003) Identification of two distinct progenitor populations in the lateral ganglionic eminence: implications for striatal and olfactory bulb neurogenesis. J Neurosci 23:167-174.

Stuhmer T, Puelles L, Ekker M, Rubenstein JL (2002) Expression from a Dlx gene enhancer marks adult mouse cortical GABAergic neurons. Cereb Cortex 12:75-85.
Sussel L, Marin O, Kimura S, Rubenstein JL (1999) Loss of Nkx2.1 homeobox gene function results in a ventral to dorsal molecular respecification within the basal telencephalon: evidence for a transformation of the pallidum into the striatum. Development 126:3359-3370.

Suzuki SO, Goldman JE (2003) Multiple cell populations in the early postnatal subventricular zone take distinct migratory pathways: a dynamic study of glial and neuronal progenitor migration. J Neurosci 23:4240-4250.

Tamamaki N, Yanagawa Y, Tomioka R, Miyazaki J, Obata K, Kaneko T (2003) Green fluorescent protein expression and colocalization with calretinin, parvalbumin, and somatostatin in the GAD67-GFP knock-in mouse. J Comp Neurol 467:60-79.

Valcanis H, Tan SS (2003) Layer specification of transplanted interneurons in developing mouse neocortex. J Neurosci 23:5113-5122.

Wichterle H, Garcia-Verdugo JM, Herrera DG, Alvarez-Buylla A (1999) Young neurons from medial ganglionic eminence disperse in adult and embryonic brain. Nat Neurosci 2:461-466.

Wichterle H, Turnbull DH, Nery S, Fishell G, Alvarez-Buylla A (2001) In utero fate mapping reveals distinct migratory pathways and fates of neurons born in the mammalian basal forebrain. Development 128:3759-3771.

Wilson SW, Rubenstein JL (2000) Induction and dorsoventral patterning of the telencephalon. Neuron 28:641-651.

Xu Q, De La Cruz E, Anderson SA (2003) Cortical interneuron fate determination: diverse sources for distinct subtypes? Cereb Cortex 13:670-676.

Yun K, Potter S, Rubenstein JL (2001) Gsh2 and Pax6 play complementary roles in dorsoventral patterning of the mammalian telencephalon. Development 128:193-205.

Yung SY, Gokhan S, Jurcsak J, Molero AE, Abrajano JJ, Mehler MF (2002) Differential modulation of BMP signaling promotes the elaboration of cerebral cortical GABAergic neurons or oligodendrocytes from a common sonic hedgehog-responsive ventral forebrain progenitor species. Proc Natl Acad Sci USA 99:16273-16278.

Zhao Y, Marin O, Hermesz E, Powell A, Flames N, Palkovits M, Rubenstein JL, Westphal H (2003) The LIM-homeobox gene Lhx8 is required for the development of many cholinergic neurons in the mouse forebrain. Proc Natl Acad Sci USA 100:9005-9010.

Zheng W, Knudsen EI (2001) GABAergic inhibition antagonizes adaptive adjustment of the owl's auditory space map during the initial phase of plasticity. J Neurosci 21:4356-4365. 